\title{
Observações sobre os Sentidos e a Essência DAS EXPERIÊNCIAS FrANCESA E BRASILEIRA NA Área da Democracia SANitária
}

\author{
COMMENTS ON THE DIRECTIONS AND THE \\ ESSENCE OF THE EXPERIENCES \\ FRENCH AND BRAZILIAN IN THE AREA \\ OF THE SANITARY DEMOCRACY
}

Emmanuel Cadeau (*)

\section{RESUMO}

Traçando um paralelo entre as experiências brasileira e francesa e os seus respectivos Sistemas de Saúde Pública, o autor analisa a participação popular na elaboração e execução das políticas de saúde, através de um novo conceito de "Democracia Sanitária". Destaca a possibilidade de intervenção do usuário através dos Conselhos e os entraves políticos, culturais ou territoriais que obstam a efetiva participação.

\section{Descritores}

Democracia sanitária; Sistema público, Saúde, Participação popular, Regionalização do sistema.

\section{ABSTRACT}

Tracing a parallel between the experiences Brazilian and French and its respective Systems of Public Health, the author analyzes the popular

(*) "Maître de Conférences" [Professor Associado] em Direito Público na Universidade de Nantes (França), Diretor do CERDES-Nantes. O CERDES (Centro de Estudos e Pesquisas em Direito Sanitário Europeu), foi constituido em 1989. Essa é a estrutura operacional de um grupo de interesse científico que tem a peculiaridade de ser composto de dois pólos, um em Nantes e outro em Bordeaux, abrindo desta forma uma rede de pesquisas inter-universidades. $O$ CERDESS-Nantes é co-dirigido por Emmanuel CADEAU e por Michel BELANGER, professor da Universidade de Bordeaux IV. Cadeau também desempenha a função de diretor do CERDESBordeaux (www.droit.univ-nantes.fr/cerdes) Entrada: 15.10.03 - Aprovado: 12.12.03. 
participation in the elaboration and execution of the health politics, through a new concept of "Sanitary Democracy". It detaches the possibility of intervention of the user through the Advice and the impediments politicians, cultural or territorial who hinder the effective participation.

\section{Key-words}

Sanitary democracy, Public system, Health, Popular participation, Regionalização of the system.

Se o termo "democracia" apareceu na língua grega, no quinto século antes de Jesus Cristo, para designar uma forma particular de organização da cidade, hoje ele se tornou polissêmico e ambíguo. A ambigüidade resulta diretamente da ambivalência do tratamento moderno do termo "democracia", oscilando permanentemente entre o conceito político e a noção jurídica, ou seja, remetendo ora aos ideais, às representações mentais, ora às normas positivas, às regras de direito.

Tomada como conceito político a democracia remeterá às democracias "popular", "ocidental", "liberal", "oriental" etc. Tomada como noção, ela será fiel à etimologia da palavra, ela remeterá às formas essenciais que permitem a implicação dos indivíduos no processo de decisão política. Far-se-á, então, referência à democracia "direta", "semidireta", "participativa", "representativa", "deliberativa" etc.

Hoje, entretanto, as duas dimensões, "de conceito" e "de noção", da democracia parecem cruzar-se permanentemente. Isso causa um questionamento cada vez mais nítido do seu caráter operacional. A democracia, como fonte de legitimidade a priori do poder político, como exigência política fundamental, cede seu lugar às democracias, técnica de legitimação a posteriori de decisões políticas diversas que não têm necessariamente como objeto o respeito da vontade e dos interesses dos destinatários dessas decisões.

A democracia sanitária não escapa a essa problemática geral, nem na França, nem no Brasil. A professora Sueli Gandolfi Dallari(1) deixa-o entender, primeiro durante conferência na Faculdade de Direito e de Ciências Políticas da Universidade de Nantes (França) ${ }^{(2)}$. Ela o confirma, a seguir, em seu artigo dedicado à experiência brasileira da democracia sanitária(3).

(1) Coordenadora científica do Núcleo de Pesquisas em Direito Sanitário da Universidade de São Paulo.

(2) Em 19 de fevereiro de 2003.

(3) DALLARI, S. G. "Le concept de démocratie sanitaire: l'expérience brèsilienne". Revue Générale de Droit Médicale, n. 12, pp. 61-65, mars 2004. Referências dessa revista no site disponivel em: $<w w w . e t u d e s-h o s p i t a l i e r e s . f r>$. 
Do ponto de vista francês, a experiência brasileira de democracia sanitária, comparada àquela da França - muito mais recente - é particularmente instrutiva, ela interroga sobre a "essência" do processo democrático na área da saúde, sobre as modalidades de sua execução (II). Do ponto de vista brasileiro, a observação da consagração jurídica da "democracia sanitária" pela lei de 4 de março de 2002, não está despida de interesse. Ela convida a uma reflexão quanto aos "sentidos" de um movimento de democratização não desprovido de ambigüidade (I).

\section{I - OS SENTIDOS DA DEMOCRACIA SANITÁRIA: LIÇÕES FRANCESAS}

A noção de "democracia sanitária" é introduzida no direito francês pela Lei n. 2002-303, de 4 de março de 2002, "relativa aos direitos dos pacientes e à qualidade do sistema de saúde"(4). A análise do Título 2 da lei, expressamente consagrado à "democracia sanitária", demonstra a vontade do legislador de concretizá-la a partir de seis eixos desenvolvidos nos diferentes campos da ação sanitária e sob registros político-jurídicos variados: direitos da pessoa (cap. 1 do título 2 da lei de 4 de março de 2002); direitos e responsabilidade dos usuários (cap. 2); participação dos usuários ao sistema de saúde (cap. 3); responsabilidade dos profissionais de saúde (cap. 4); diretrizes da política de saúde (cap. 5); organização regional da saúde (cap. 6).

Dois blocos de tendências distinguem-se, então, se aceitarmos inverter a ordem dos capítulos. Os primeiros dizem respeito à democracia sanitária stricto sensu, os demais vislumbram-na lato sensu.

\section{A DEMOCRACIA SANITÁRIA STRICTO SENSU}

No sentido estrito do termo, a democracia como sistema político organiza o encontro entre o demos (povo) e o kratos (poder). Ela remete, portanto, a várias formas de democracias possíveis, que se acredita permitirem a implicação dos indivíduos no processo de decisão política e se fala, então, em democracia "direta", "semidireta", "participativa", "representativa", "deliberativa" etc.

A Lei de 4 de março de 2002 esforça-se para materializar a democracia sanitária assim entendida procurando revalorizar o papel político do cidadão no processo de definição das políticas públicas sanitárias. 0 legislador não escapa, contudo, da abordagem francesa tradicional da democracia que privilegia a democracia representativa. Assim, para organizar a "participação dos usuários no sistema de saúde", o legislador consagra direitos específicos para as associações de usuários que preen-

(4) J. O. [Diário Oficial] 5 mars, p. $4.118 \mathrm{~s}$. 
cham certos critérios de representatividade (artigos L. 1114-1 a L.1114-4 Código de Saúde Pública - CSP). Além disso, a lei renova as modalidades de definição das "diretrizes da política de saúde pública" (artigos L. 1411-1 a L. 1411-6, CSP). Também aí a lógica institucional e representativa domina, uma vez que a democratização do sistema de saúde passa por um "Alto Conselho de Saúde", depois da instalação, em cada região, de um "Conselho Regional de Saúde" e pela "Conferência Nacional de Saúde", mesmo que, é necessário reconhecer, essas duas últimas instituições tenham, sobretudo, a missão de "organizar ou contribuir na organização de debates públicos que permitam a manifestação dos cidadãos sobre questões de saúde ou de ética médica".

\section{A DEMOCRACIA SANITÁRIA LATO SENSU}

Tomando conhecimento da transformação radical da relação médico/ paciente, a Lei de 4 de março de 2002, que procura, de certo modo, acompanhar a passagem da era do humanismo àquela do consumismo, esforça-se em seguida para pôr fim ao que alguns chamam de "paternalismo médico".

No espírito do legislador, o reequilíbrio desejado deveria passar primeiro por uma confirmação solene dos mandamentos essenciais à atividade de cuidados: "a pessoa doente tem direito ao respeito de sua dignidade" (art. L. 1110-2, CSP); "nenhuma pessoa pode ser objeto de discriminação no acesso à prevenção ou aos cuidados" (art. L. 1110-3, CSP); "toda pessoa tem, levando em conta seu estado de saúde bem como a urgência das intervenções que o caso necessite, o direito de receber os tratamentos mais apropriados" (art. L. 1110-5, al.1, CSP); "toda pessoa tem o direito de receber os cuidados e tratamentos visando aliviar sua dor" (art. L. 1110-5, al. 3, CSP); ou, ainda, "os profissionais de saúde lançam mão de todos os meios de que dispõem para garantir a cada um uma vida digna até sua morte" (art. L. 1110-5, al. 4, CSP).

Além disso, o legislador aplica ao ancestral "colóquio singular" entre o médico e o paciente, um regime de "co-decisão" destinado a realizar o re-equilíbrio de uma situação julgada desigual. "Toda pessoa toma, junto ao profissional de saúde e a partir das informações e opções terapêuticas que ele Ihe fornece, as decisões que dizem respeito à sua saúde" proclama, assim, o novo artigo L. 1111-7 do Código de Saúde Pública.

Sobre tais fundamentos, o título 2 da Lei de 4 de março de 2002, declina os direitos do paciente, que é tido agora como pessoa humana sob os cuidados de um sistema de saúde no qual as responsabilidades, tanto dos profissionais de saúde (cap. 4), quanto dos usuários (cap. 2), foram redefinidas.

A expressão "democracia sanitária" não deve, portanto, iludir, principalmente na França. O principal objeto da Lei de 4 de março de 2002 encontra-se fixado no objetivo de reequilibrar a relação "pessoas medicamen- 
te dependentes" / "poder médico". Assim, não se trata, verdadeiramente, (ainda?) de "democracia", no sentido estrito. O que se objetiva não são, principalmente, as modalidades de participação no exercício do poder político no domínio da saúde. O objetivo é, antes disso, a identificação de um novo estatuto da "pessoa humana medicamente dependente".

\section{II - A ESSÊNCIA DA DEMOCRACIA SANITÁRIA: LIÇÕES FRANCO-BRASILEIRAS}

A observação cruzada das experiências brasileira e francesa de democracia sanitária, compreendidas como políticas públicas submetidas a um enquadramento jurídico substancial, sugere duas séries de indagações. A primeira diz respeito à escolha da forma de expressão dominante de democracia sanitária: democracia sanitária participativa e/ou representativa? A segunda refere-se à identificação do território democraticamente pertinente em matéria sanitária.

\section{A ESCOLHA DAS FORMAS DA DEMOCRACIA SANITÁRIA}

Um dos primeiros canteiros de obras que acompanha o nascimento da jovem democracia brasileira, em 1985, por ocasião da convocação da Assembléia Constituinte, consiste na renovação da organização do sistema de saúde no âmbito do estado federal brasileiro. Uma das originalidades dessa organização federal reside exatamente na inscrição do artigo 198 da Constituição de 1988 do princípio de participação popular, princípio igualmente retomado pela Lei $n$. 8.142/90 relativa ao financiamento da saúde e à participação popular. Decorre desse princípio uma participação paritária dos usuários dos serviços de saúde, dos representantes do governo e dos profissionais de saúde no conjunto das instâncias que avaliam, controlam, financiam a política de saúde brasileira e isso em todos os níveis descentralizados(5).

Hoje se observa, entretanto, de um lado um retraimento progressivo dos brasileiros do debate democrático direto, que não parece mais despertar a mesma mobilização que nos anos 80-90; por outro lado, depois de ascensão ao poder, em outubro de 2002, de um novo governo, de esquerda, dirigido por Luiz Inácio Lula da Silva, uma vontade política de redinamização da democracia representativa, na área da saúde, em contraponto da democracia sanitária participativa original(6).

(5) Assim, o direito brasileiro conhece, por exemplo, a noção muito curiosa para um francês, de "orçamento participativo".

(6) Ela passa, essencialmente, pela redefinição dos modos de funcionamento das três principais instituições que caracterizam a democracia sanitária no Brasil: as conferências de saúde, os conselhos de saúde, os fundos de saúde. Para uma descrição dessas três instituições, ver: DALLARI, S. G., op. cit., p. 64. 
Enquanto a democracia sanitária, no Brasil, primeiro exprimiu-se de modo participativo, antes de explorar as vias de democracia representativa, na França o caminho inverso parece ter sido trilhado.

Classicamente distingue-se a "democracia participativa" da "democracia representativa" para acentuar a diferenciação dos modos de implicação do povo soberano no exercício do poder. A democracia representativa supõe que o povo exerce a soberania por intermédio de seus representantes, os quais são eleitos no quadro das instituições que, num território determinado, têm por princípio uma vocação geral para se ocuparem dos "assuntos da cidade". A democracia participativa, ao contrário, implica por sua vez que o povo soberano seja chamado a participar diretamente no exercício do poder de decisão. Nessa lógica, o fato de ser cidadão permite exprimir diretamente uma escolha relativa à organização geral da sociedade. Falaremos nesse caso de "democracia participativa direta".

$\mathrm{Na}$ França, é a democracia sanitária representativa que se manifesta primeiro. A participação procurada não é necessariamente a do povo soberano em seu conjunto, mas, mais precisamente, das categorias de cidadãos solicitados, seja em razão da perícia que lhes é própria numa área determinada, seja porque eles são representantes - eles mesmos eleitos - do que podemos chamar de "corpos intermediários" mais ou menos instituídos tais como os sindicatos ou as organizações profissionais. A participação deles é legitimada pela idéia, segundo a qual o fato de ser cidadão $e$ ator na cidade permite participar na organização do campo de atividade em questão.

$\mathrm{Na}$ França hoje se observa, entretanto, por diversas razões que não vêm ao caso analisar aqui, um desenvolvimento significativo dos mecanismos de democracia participativa direta. Por exemplo: a experiência das Conferências Regionais de Saúde, dos "fóruns-cidadãos" e, mais globalmente, o movimento impulsionado pela Lei de 4 de março de 2002, acima mencionada, "relativa aos direitos dos doentes e à qualidade do sistema de saúde"

Assim, não escapa ao observador que as experiências francesa e brasileira de democracia sanitária, ao mesmo tempo em que oferecem perspectivas inversas, se defrontam com um obstáculo idêntico, que é o da participação cidadã. A primeira é freada pela vontade política que não instaurou, por enquanto, os fundamentos técnicos reais da democracia sanitária. Entenda-se que, na França, mesmo depois da Lei de 4 de março de 2002, a lógica representativa nunca foi totalmente apagada das modalidades de implementação da própria democracia participativa ${ }^{(8)}$.

Quanto à segunda, a experiência brasileira, que desde sua origem ela foi dotada de procedimentos adequados para assegurar, em teoria, a

(7) CADEAU, E. Région et démocratie sanitaire: quels rapports? RGDM, n. 9, pp. 5-30, 2003.

(8) A instauração e a direção do processo participativo permanecem sob a responsabilidade dos representantes eleitos. Por outro lado, será que isso poderia e deveria ser de outra forma? Questões que poderiam parecer "politicamente incorretas", tanto é forte a impregnação demagógica do conceito de democracia sanitária, na França. 
participação direta dos cidadãos, hoje sofre de um "desencanto" que afasta progressivamente os brasileiros dos lugares de debates. O impasse estaria bem aí, uma vez que esse mal é descrito como o fator que afligiu a democracia desde seus primórdios ${ }^{(9)}$.

\section{A ESCOLHA DO "TERRITÓRIO DEMOCRATICAMENTE PERTINENTE"}

A França é um Estado unitário; o Brasil é um Estado federal. Apesar da natureza diferenciada desses dois tipos de estruturas estatais, a implementação da democracia sanitária supõe, em ambos os casos, uma escolha fundamental, aquela do "território democraticamente pertinente". No quadro do estado federal brasileiro, essa escolha parece, a priori, mais simples que no quadro do estado unitário francês, isso em razão dos próprios princípios do federalismo institucional. Os princípios do federalismo institucional são três: trata-se dos princípios de "superposição", de "participação" e de "autonomia". O princípio de superposição significa que num mesmo território estão superpostas duas ordens jurídicas distintas das quais dependerá o cidadão. O princípio de participação tem por vocação lembrar que o federalismo baseia-se na solidariedade entre os membros que compõem a entidade federal, que por essa razão deverão ter a possibilidade de se manifestar nos limites dessa entidade. Por fim, o princípio de autonomia indica que, em razão de o federalismo institucional ter por vocação cimentar as solidariedades entre diferentes entidades, sem questionar suas peculiaridades, suas especificidades; é necessário garantir a cada uma dessas entidades uma real autonomia de decisão.

A implantação desses três princípios na organização da democracia sanitária brasileira deveria, em tese, conduzir a uma ventilação clara das competências entre as diferentes esferas de intervenção e, portanto, à identificação do espaço político mais adaptado e mais pertinente para a eclosão da democracia sanitária. Ora, parece que, na prática, as coisas são mais complexas. Isso vale, em primeiro lugar, para a democracia sanitária considerada sob o aspecto representativo: a União, os Estados, os Municípios (em número de 5000) dispõem de competências legislativas concorrentes na área da saúde. Desta forma, se a União elaborar a norma geral, os Estados e os Municípios podem complementá-la em função de interesses locais. Do mesmo modo, sob o ângulo participativo, a implementação da democracia sanitária no Brasil não escapa à problemática da superposição de competências. Lembrando que as "conferências de saúde", os "conselhos de saúde" e os "fundos de saúde" constituem as "três instituições características da democracia sanitária no Brasil", a professora Dallari acrescenta que essas instituições se reproduzem em três esferas políticas do Estado(10). Isso prejudica a leitura dos mecanismos de

(9) ROSANVALLON, P. “Le peuple introuvable". Paris: Gallimard, folio histoire, 1998.

(10) DALLARI, S. G., op. cit., p. 64 
expressão da democracia sanitária e comporta um risco: o de ver se desenvolver uma pluralidade de discursos divergentes a respeito dos problemas comuns, em razão, principalmente, da grande disparidade de competências das pessoas que participam, no Brasil, nas diferentes instâncias de um Município, ou de um Estado a outro.

A multiplicidade dos locais de organização da democracia sanitária não se constitui necessariamente, portanto, numa garantia de emancipação ideal da democracia sanitária.

A França parece ter compreendido a lição. Saberá ela colocá-la em prática? As experiências de democracia sanitária, concentradas essencialmente na esfera administrativa, naquela região, permitem ostentar hoje um certo otimismo, à falta de um otimismo certo(11). "Regionalização do sistema de saúde" de um lado, "democratização" desse mesmo sistema de outro lado, ambos os movimentos se cruzam. Disso dão testemunho a institucionalização das "conferências regionais de saúde", pelos decretos de 1996, a organização, no quadro da Região, dos "fóruns cidadãos", por ocasião dos Estados Gerais da Saúde (outubro de 1998 a março de 1999), ou ainda, os trabalhos de reflexão consagrados a questões de saúde conduzidos por um número crescente de Conselhos Econômicos e Sociais Regionais (CESR) ${ }^{(12)}$. Dando validade a essas experiências, a Lei de 4 de março de 2002, acima referida, faz da "organização regional da saúde" (arts. 35 a 44) um pilar da instauração da "democracia sanitária". Desse modo, ela prepara o terreno para o reforço vindouro das competências das coletividades territoriais francesas em matéria sanitária e, principalmente, ela institui os "Conselhos Regionais de Saúde"(13). A "Lei de 4 de março de 2002 confirma dessa forma a escolha do espaço regional para o reforço da democracia sanitária"(14).

$\mathrm{Na}$ França, a democracia sanitária direta "territorializada" está, portanto, em andamento. Se ela se torna uma exigência política inevitável, supõe também uma reflexão quanto às modalidades de sua implementação bem como sobre a escolha do território pertinente. Ela sugere, principalmente, a invenção de novos instrumentos de participação e de deliberação. Nessa grande empreitada, a observação das experiências estrangeiras, a do Brasil particularmente, está longe de ser supérflua.

(11) Em razão, exatamente, da própria ambigüidade do conceito de democracia sanitária (ver: CADEAU, E. "La démocracie sanitaire: erreur, commodité ou écart de langage?" Revue Générale de Droit Medicale, n. 12, pp. 9-16, mars 2004).

(12) Ver CADEAU, E. "Territoire et democratie: l'expérimentation régionale de la démocratie sanitaire délibérative". In: LE RENOUVEAU de l'aménagement du térritoire. Paris: Ed. L'Harmattan, 2002, pp. 245-290. (Coll. Logiques juridiques).

(13) Eles substituem as Conferências Regionais de Saúde. A criação dessa nova instância deve permitir o debate, num único local, dos diversos aspectos da política regional de saúde e contribuir para definir as prioridades regionais.

(14) Ver: "Aménagement du territoire et établissement de santé", Relatório no Conselho Econômico e Social apresentado em nome da Seção das economias regionais e da organização do território, por M. Michel PICARD, relator, em 12 de maio de 2004, p. 77 . 


\section{REFERÊNCIAS BIBLIOGRÁFICAS}

CADEAU, E. "La démocracie sanitaire: erreur, commodité ou écart de langage?" Revue Générale de Droit Medicale, n. 12, pp. 9-16, mars 2004. "Région et démocratie sanitaire: quels rapports?" $R G D M, \mathrm{n}$. 9, pp. 5-30, 2003.

"Territoire et democratie: l'expérimentation régionale de la démocratie sanitaire délibérative". In: LE RENOUVEAU de l'aménagement du térritoire. Paris: Ed. L'Harmattan, 2002, pp. 245-290. (Coll. Logiques juridiques).

DALLARI, S. G. "Le concept de démocratie sanitaire: l'expérience brésilienne". Revue Générale de Droit Médicale, n. 12, pp. 61-65, mars 2004. Referências dessa revista no site disponivel em: <www.etudes-hospitalieres.fr>.

ROSANVALLON, P. "Le peuple introuvable". Paris: Gallimard, folio histoire, 1998. 